\title{
Sensory Properties of Cold Press Moringa Oil
}

\author{
Janaki S (M. Phil., NET) \\ Department of Homescience, Mother Teresa Women's University, Chennai - 15, India
}

\begin{abstract}
Moringa oil has the potential to be utilized as an additional source of edible oil. Nutritional importance of moringa oil as the capability to be in addition with olive oil in the Indian market, which is being imported. Due to its physico-chemical properties it can be used as an edible oil. The present research was designed to extract and determine cold press moringa oil sensory properties. Moringa oil was extracted by traditional method of cold press. According to literature moringa oil, a high mono unsaturated fatty acid (oleic acid) oil which resembles olive oil in properties was compared with olive oil. Acceptance of moringa oil was compared with olive oil by sensory evaluation of roasted potato and French fry recipes. The scores obtained were subjected to student's t test and significant difference of moringa oil compared with olive oil.
\end{abstract}

Keywords: Moringa oil, olive oil, edible oil, sensory properties, drumstick oil, ben oil

\section{Introduction}

Vegetable oils constitute an important part of human livelihood all over the world. The widening gap between demand and supply necessitates the need for alternate sources of edible oils to augment global production. To meet the growing demand of fats and oils, concerted efforts have been made to increase the seed yield and by tapping minor oilseeds of tree origin. Due to ever diminishing sources of fats and oils, there is the growing need for the search of new sources of oil as well as exploiting sources that are currently unexploited in order to supplement the existing ones. Moringa seeds has good physicochemical properties in such a way that no additional processing operations methods will be needed for the oil. The oil has good quantity of oleic acid and omega 3; therefore it can be used for frying and other food purposes. Moringa oil is recommended for frying purposes because it contains high amount of oleic acid (57 percent) and omega 3 (13.28 per cent) (Khattab and Shakak, 2012). The present study was designed to extract and determine sensory properties of cold press moringa oil which was compared with olive oil, due to its similarities of the properties.

\section{Review of Literature}

Moringaoleifera seeds contain about 42 per cent of a brilliant yellow, high oleic acid crude oil having a pleasant, peanut like flavour. The oil consists of 82 per cent unsaturated fatty acids, 70 per cent of which is oleic acid (Tsaknis et al., 1998; Foidl et al., 2001; Anwar et al., 2006; Rahman et al., 2009). Apart from the emphasis of modern nutrition on oils that contain high amount of unsaturated fatty acids, high oleic acid oils are known to be healthy alternatives to hydrogenated vegetable oils (Tsaknis et al., 1998; Rahman et al., 2009). Olive oil, the widest known in this category, is seldom used for frying because of its high cost. There are several reports on the composition and characterisitics of moringaoleifera seed oil varietites from different countries of origin, e.g., India (Lalas and Tsaknis et al., 2002), Malaysia (Abdulkarim et al., 2005), Pakistan (Anwar et al., 2006; Manzoor et al., 2007), Bangladesh (Rahman et al., 2009) considering its prospect as an alternative vegetable oil source. Quality characteristics of moringa seed oils from Indian cultivar (PKM-1) and an
African cultivar grown in similar agro-climatic conditions of Argentina has also been reported (Ayerza, 2011).

\section{Materials and Methods}

The moringa kernels were purchased from private exporter, Coimbatore. The dry kernels undergone traditional cold press oil extraction. Before the onset of sensory evaluation, the two potato recipes (deep fried french fry and shallow fry roasted potato) were standardized. Standardized recipes were quantified for sensory evaluation session using factor method.

A total of sixty panelist were selected, semi-trained $(\mathrm{N}=30)$ and untrained panelist $(\mathrm{N}=30)$ were participated in the research. For semi-trained panelist, staffs and students of Department of Home Science of Mother Teresa Women's University, Chennai and students of reputed colleges of Department of Home science were selected. Untrained panelist were staffs and students of other Departments of Mother Teresa Women's University, Chennai and residents of Porur, Chennai were involved, as the area was familiar to the researcher. Panel score sheet with a numerical descriptive scale of rating was developed, using quality parameters such as texture acceptability, flavour intensity, crispiness, friability, colour, taste and over all preference. Ranking scale was employed in order to know the preference order of potatoes prepared with different oils. Hedonic rating scale was used to measure the panelist acceptability of potatoes on 9 points, ranging from 'like extremely' to 'dislike extremely'. Willingness of the panelist were confirmed through informed consent form. A session was conducted to educate the panelist about the score sheet for descriptive terms (quality parameters), numeric rating scale and hedonic rating scale.

The shallow fried roasted potato recipes prepared with moringa oil(EO), olive oil(CO) oils were coded as AA1 and AA2 respectively. Deep fried french fries prepared with $\mathrm{CO}$ and EO oils were coded as BB2 and BB3 respectively. The sensory evaluation of the potatoes prepared using different oils were carried out among semi-trained $(\mathrm{N}=30)$ and untrained panelist $(\mathrm{N}=30)$ by $10 \mathrm{am}$. The prepared potatoes weighing 50 grams per subject of roasted potato sample and 20 grams (10 to 12 slices) per subject of french fries were placed in silver laminated no.8 paper plates with codes,

\section{Volume 4 Issue 12, December 2015}




\section{International Journal of Science and Research (IJSR) \\ ISSN (Online): 2319-7064}

Index Copernicus Value (2013): 6.14 | Impact Factor (2014): 5.611

room temperature water, slice of carrot, napkin and score sheet with pen. Panelist were instructed to rinse palates with water and eat a slice of carrot before and between tasting and retasting of samples to avoid flavour carry over. The scores obtained were subjected to student ' $\mathrm{t}$ ' test and significant difference of moringa oil compared with olive oil.

\section{Results and Discussion}

Sensory evaluation conducted using score sheet, applied on two methods of potato frying (shallow fry and deep fry) evaluated by semi-trained and untrained panelist. Numeric descriptive scale results of mean values of potato recipes prepared by different oils were compared statistically for organoleptic properties and rank correlation and percentage score of hedonic scale were discussed.

There was a significant difference in the texture attributes between EO and CO of shallow fry potatoes by semi-trained panelist but no significant difference in flavour, crispness, friability, colour, taste and over all preference. There was no significant difference in the total score between EO and CO of shallow fry potatoes by semi-trained panelist. The correlation value for texture, flavour, crispness, colour, friability, taste and overall preference of sensory attributes and total score between EO and CO shallow fry potatoes by semi-trained panelistshowed a positive correlation.

There was no significant difference in the sensory attributes and total score of shallow fry potatoes between EO and CO by untrained panelist. There was a positive correlation in sensory attributes and in total score between shallow fry potatoes by untrained panelist.

There was no significance difference in the sensory attributes and total score of deep fry potatoes with EO, CO by semi-trained panelist. A positive correlation in sensory attributes and in total score between deep fry potatoes with different oils by semi-trained panelist.

There was no significant difference in sensory attributes of deep fry potato prepared with $\mathrm{EO}$ and $\mathrm{CO}$ by untrained panelist. There was no significant difference in total score of deep fry potatoes prepared with EO and CO by untrained panel judges. A positive correlation between the total score and sensory attributes like texture, flavour, crispness, friability, colour and taste of deep fry potatoes prepared with EO and CO by untrained panelist. There was a weak positive correlation in overall preference between deep fry potatoes prepared with $\mathrm{EO}$ and $\mathrm{CO}$ by untrained panelsit.

The percentage score of shallow fried potatoes with different oils by semi-trained panelist $(\mathrm{N}=30)$ showed that EO was liked extremely by $33 \%$ panelist, $43 \%$ like very much, $20 \%$ like moderately and $4 \%$ like slightly. The $\mathrm{CO}$ prepared shallow fry potatoes like extremely by $27 \%$ panelist, like very much by $33 \%$, like moderately by $20 \%$ and $10 \%$ liked slightly.

The percentage score of shallow fried potatoes prepared with different oils evaluated by untrained panelist $(\mathrm{N}=30)$ reported that $33 \%$ of panelist like extremely the EO prepared potatoes, like very much by $43 \%$ of panelist, $10 \%$ of panelist like moderately and $14 \%$ like slightly. Potatoes prepared with CO liked extremely by $35 \%$ panelist, like very much by $45 \%$, like moderately by $10 \%$ and $10 \%$ like slightly. Majority of semi-trained and untrained panelist like very much the shallow fry potatoes prepared with different oils.

The percentage score of deep fried potatoes with three different oils evaluated by semi-trained panelist $(\mathrm{N}=30)$ stated that $\mathrm{CO}$ prepared potatoes where liked extremely by $33 \%$, like very much by $33 \%, 27 \%$ like moderately and like slightly by $7 \%$ of the panelist. $33 \%$ of the panelist like extremely the potatoes prepared with EO, like very much $27 \%$, like moderately $23 \%$ and $17 \%$ of the panellist like slightly.

The percentage score of deep fried potatoes with three different oils evaluated by untrained panelist $(\mathrm{N}=30)$ reported that potatoes prepared with $\mathrm{CO}$ were liked extremely by $37 \%$ of panelist, like very much by $33 \%$, like moderately by $24 \%$ and $6 \%$ like slightly. The EO prepared potatoes were liked extremely by $37 \%$ of panelist, $30 \%$ of them like very much, $23 \%$ like moderately and $10 \%$ like slightly. Majority of semi-trained and untrained panelist reported that they like extremely the deep fried potatoes with different oils. No dislike reported for deep fry potatoes among semi-trained and untrained panelist.The rank correlation result showed an equal preference of potatoes prepared with different oils in semi-trained and also in untrained panelist.

Cold pressed and hexane extracted moringa seed oils (CPMSO and HEMSO) were evaluated for their physicochemical and stability characteristics. The oxidative, thermal and frying stabilities of the CPMSO were compared with commercial raw and refined groundnut oil (GNO and RGNO). The CPMSO was of adequate thermal stability and better oxidative stability as it showed $79 \%$ lesser peroxide formation than GNO. The frying stability of CPMSO was better as it showed lower increase in free fatty acid, peroxide value and colour than RGNO after frying (Ogunsina et al., 2011).

A number of panellists were chosen to taste potatoes and cod for the overall characterisation of the organoleptic properties (appearance, colour, flavour and texture) aftereach batch had been fried. A taste panel score sheet with a numerical scale of rating was developed, using descriptive terms against each numerical score for each quality parameter. Throughout the frying time the overall acceptance scores showed a significant difference in overall acceptance of fried potatoes with cold pressure and chloroform-methanol oil after 5 days of frying, while this difference was significant after 4 days of frying with nhexane oil. The overall acceptance scores showed that fried cod was unacceptable after having been fried in oil for 5 days in cold pressure oil, after 4 days of frying in chloroform-methanol oil and after 3 days in n-hexane oil. The panel scores confirmed that cold pressure oil is the most suitable oil for repeating frying compared to the other oils involved in this study (Tsakins et al., 1999).

\section{Volume 4 Issue 12, December 2015}




\section{International Journal of Science and Research (IJSR) \\ ISSN (Online): 2319-7064}

Index Copernicus Value (2013): 6.14 | Impact Factor (2014): 5.611

\section{Result}

Due to high dependency of humans on oil for both domestic and industrial uses, there is need to look for another source of oil. The functional properties and nutritional importance of moringa seed oil make it a better choice to be another source of oil for healthy cooking especially for the developing countries in Asia and Africa, where its availability is more and common.

\section{References}

[1] Abdulkarim, S.M., Long, K., Lai, O.M., Muhammas, S.K.S and Ghazali, H.M. Somephysico-chemical properties of Moringaoleifera seed oil extracted using solvent and aqueous enzymatic methods. Food Chemistry, 2005, 93, 253-263.

[2] Anwar F, Syeda NZ, Umer R. Characterization of Moringaoleifera seed oil from drought and irrigated regions of Punjab, Pakistan. GrasasAceites, 2006, 57, 160- 168.

[3] Ayerza, Ricardo. Seed yield components, oil content, and fatty acid composition of two cultivars of moringa (Moringaoleifera Lam.) growing in the Arid Chaco of Argentina. Industrial Crops and Products, 2011, 389394.

[4] Foidl, N., Makkar, H.P.S. and Becker, K. Potential of Moringaoleifera in agriculture and industry. Potential of Moringa products development, 2001, pp: 20.

[5] Khattab MMA and Mahdi Abbas SaadShakak. Effect of Frying on the Physicochemical Properties of Moringaoleifera, Groundnut (Arachishypogaea) Ail and their Blends, Journal of Science and Technology, 2012, Vol. 13, December.

[6] Lalas, S. and J. Tsaknis. Characterization of Moringaoleifera seed oil variety Periyakulam-1. J. Food Comp. and Anal., 2002, 15: 65-77.

[7] Manzoor M, Anwar F, Iqbal, Bhnager MI. Physicochemical characterization of Moringaconcanensis seeds and seed oil. J Am Oil ChemSoc 2007; 84:413-9.

[8] Ogunsina BS, Indira TN, Bhatnagar AS, Radha C, Debnath $S$ and Gopala Krishna AG. Qualitycharacteristics and stability of Moringaoleifera seed oil of Indian origin. Journal of FoodScience and Technology. 2011, DOI 10.1007/s13197-011-0519-5.

[9] Rahman, Ismail MM, et al., Physico chemical properties of moringaoleifera lam. Seed oil of the indigenouscultivar of Bangladesh. J of Food Lipids. 2009, 540553.

[10] Tsaknis, J., S. Lalas, V. Gergis, V. Dourtoglou and V. Spiliotis. A total characterization of Moringaoleifera Malawi seed oil. La RivistaItalianasostanza Grasse, 1998, 75: 21-27.

[11] Tsaknis, J., S. Lalas, V. Gergis, V. Dourtoglou and V. Spiliotis. Characterization of Moringaoleifera variety Mbololo seed oil of Kenya. J. Agric. Food Chem., 1999, 47: 4495-4499.

\section{Author Profile}

Janaki $\mathbf{s}$ is Nutrition faculty at Vlcc Educational Institute, Adyar, Chennai. She is M.Phil. and has qualified NET. Her area of specialization includes foods and nutrition. Her research interest is in Clinical Nutrition and Food Science 